\title{
Effect Of Excavation As Treatment For Hydrocarbon Polluted Soil
}

\author{
${ }^{1}$ Uzoekwe, S.A., ${ }^{2}$ Anekwe, U.L. \\ ${ }^{I}$ Department of Chemistry, Federal University Otuoke, Bayelsa Sate, Nigeria. \\ ${ }^{2}$ Department of Physics, Federal University Otuoke, Bayelsa State, Nigeria.
}

\begin{abstract}
Environmental pollution by petroleum hydrocarbon is a major challenge in most nations of the world with such pollutant exerting acute and chronic toxicity on soil properties and micro biota. Using Ofagbe town located in Delta State, Nigeria, as a case study, it was observed that excavation could be a palliative measure in the management and treatment of hydrocarbon polluted soil. The values of physicochemical parameters ( $\mathrm{pH}$, total nitrogen, chloride, electrical conductivity and organic carbon) reduced considerably 30 days and 60 days after excavation at a depth of $0-15 \mathrm{~cm}$ and $15-30 \mathrm{~cm}$. The results also showed that crude oil impacted soil samples examined 30, 60, 90 and 120 days after excavation dropped significantly in its hydrocarbon counts against samples collected before excavation. Hence, excavation is a possible remedy to crude oil polluted soil.
\end{abstract}

Keywords: Hydrocarbon, Polluted Soil, Excavation, Physicochemical and Oil Spill.

\section{Introduction}

Oil spillage is a term used to describe an accidental discharge of crude oil into the natural environment [1]. Oil spillage causes damage to the soil for a very long period of time. Spillage of crude oil into arable lands in Nigeria has been reported since 1971 [2]. Oil exploration and activities have been concentrated in the Niger Delta of Nigeriawith over 1000 oil wells and over 47,000 km of oil and gas flow stations[3]. One of the methods of knowing whether an area is contaminated or polluted is by estimating the total extractable hydrocarbon content of the impacted soil [4]. Nigeria produces both the light and the medium crude oil and each can exert acute or chronic toxicity or both on soil properties [2;5]. Oil spillage may be attributed to flow line/pipeline leakages, blow outs, sabotage to well heads, flow lines and tanker loading systems [6;7]. In Nigeria, the major cause of oil spill is lack of maintenance of oil pipelines and storage tanks as well as vandalism [1]. Most pipelines from flow stations in Nigeria are obsolete, being over20 years old making them corrosion prone and consequently, leakage of petroleum products [8]. Oil Pipeline Vandalism is a threat to Nigerian National Security [9]

According to Directorate of PetroleumResourcesAnnual Report(1997) [9], over 60,000 spills have occurred in Nigeria during the over 40 years of oil exploration. Between 1976 and 1996, spills of 2.4x $10^{8}$ barrels of crude oil occurred from 647 incidents with only 54706038 barrels recovered, implying that 182040666 barrels of oil were lost to the ecosystem [10]. This occurrence of oil spillage on land is of major concern as it could result amongst other things in a substantial increase in organic load. The alkalinity, acidity and salinity regimes of oil spills and discharged effluents may alter the $\mathrm{pH}$ of the receiving soil body. Oil spills may also introduce heavy metals such as copper, nickel and mercury which could have serious toxic effects on the biota[11].

The southern part of Nigeria, especially the Niger Delta is an area of active petroleum exploitation activities, thus exposing the lands in these areas to risk of contamination from petroleum and associated pollutants. Niger Delta is one of the world's largest deltas; it is a vast coastal plain covering over 70,000 square kilometers in the central part of southern Nigeria [12]. Endowed with immense natural resources, especially hydrocarbon deposits, the region produces over 2 million barrels of crude oil per day, accounting for over $90 \%$ of the Nigeria's total export earnings. With an extensive network of over 900 producing oil wells, 11,000 km aging flow lines and over 160 flow stations, which cut across about 800 oil-producing communities. The region has become synonymous with pollution of aquatic and terrestrial ecosystem, recording an estimated average of 221 oil spills per annum [12;13].

Because of the challenges posed by oil spillage to the soil, ecosystem and the environment, different researchers have suggested various strategies for removingthese compounds from the environment.Amadi, (1990) [14] and Amadiet al., (1993) [15], agreed that adverse effects of crude oil inundation of soils could be ameliorated by nutrient supplementation. Chemical reclamation of the crude oil inundated soils from the Niger Delta region of Nigeria was optimally enhanced at $2 \%(\mathrm{w} / \mathrm{w})$ and $3 \%(\mathrm{w} / \mathrm{w})$ supplementation with $\left(\mathrm{NH}_{4}\right)_{2} \mathrm{SO}_{4} \cdot \mathrm{KH}_{2} \mathrm{PO}_{4}$ and $\mathrm{KCl}(\mathrm{N}-$ $\mathrm{P}-\mathrm{K}$ ) fertilizer for NO3-N and potassium respectively [16]. Amelioration of crude oil polluted soils with poultry manure may be advantageous [17]. Biodegradation, especially by microbes is one of the primary mechanisms of ultimate removal of petroleum hydrocarbons from polluted environment $[18 ; 19]$. The acceleration of this natural 
process is the objective of bioremediation efforts. Also, phytoremediation is a new technology that promises effective and inexpensive clean up and restoration of oil polluted environment. It involves the use of plants that aid in the restoration of contaminated ecosystems [20]. All this methods are known to be expensive. Therefore, this work is aimed at determining the effect of excavation as affordable potential treatment for petroleum polluted soil.

\section{i. Study Area}

\section{Experimental Method}

Ofagbe town is located inIsoko North Local Government Area of Delta state, Southern Nigeria(latitude $5^{\circ}$ $33^{\prime} \mathrm{N}$ and $5^{\circ} 55^{\prime} \mathrm{N}$, and longitude $6^{\circ} 21^{\prime} \mathrm{E}$ and $6^{\circ} 35^{\prime} \mathrm{E}$ ) and is a rural farming community about $15 \mathrm{kmEast}$ South of Ozoro, the local government headquarters. Over 10,000 barrels of crude oil spilled on a farm land of the rural community from $19^{\text {th }}$ to $23^{\text {rd }}$ of November 2010.The vandalized pipe line that caused spillage belongs to one of the indigenous oil company.

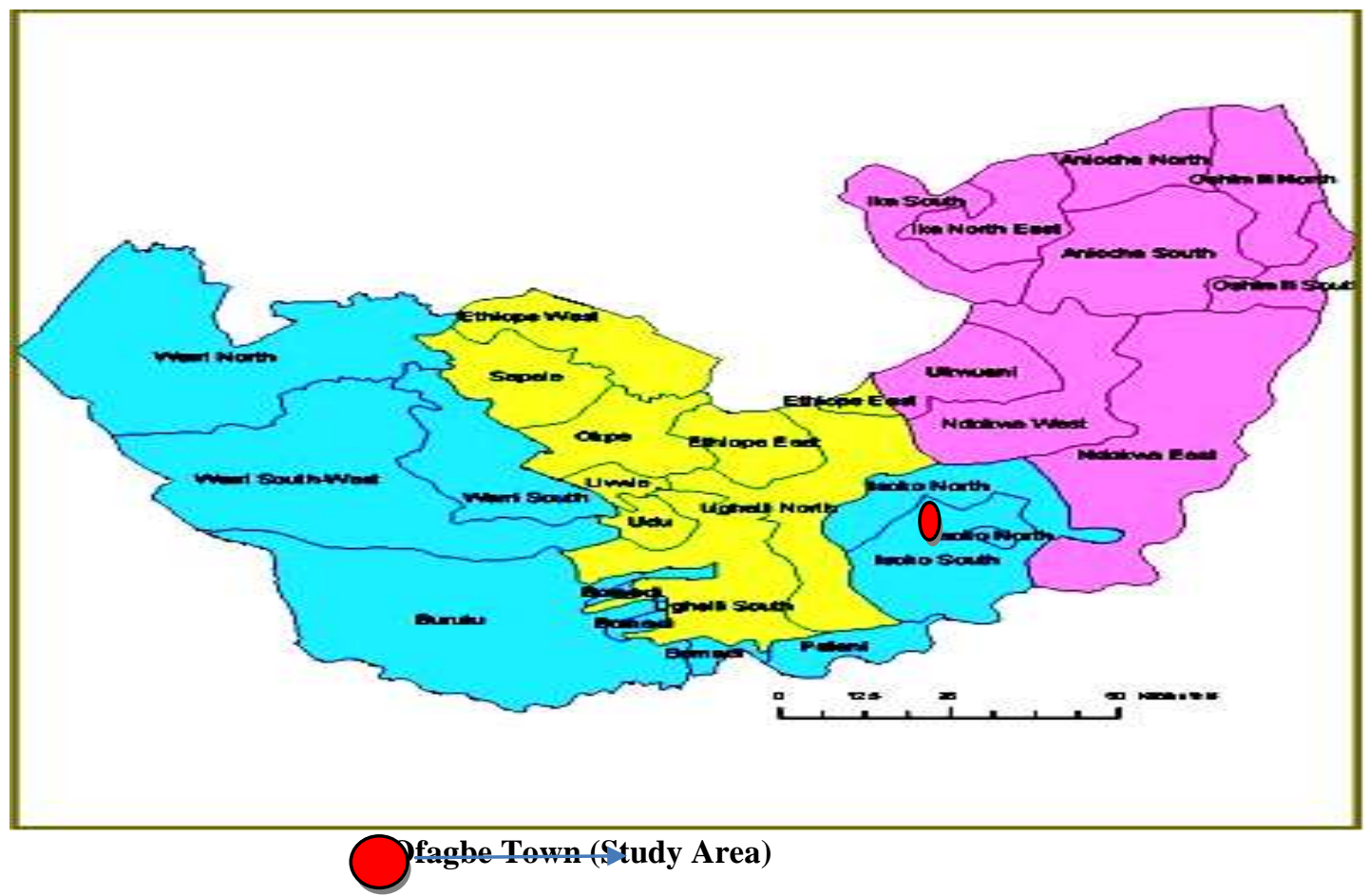

Figure 1: Map of Delta State, Nigeria showing the location of Ofagbe Town

\section{ii. Sampling Design and Soil Collection}

Samples were collected from four broad zones, heavily impacted zone, medium impacted zone, little impacted zones and no impact zone (control).100g of soil samples were collected at the surface (i.e 0-15 cm) and $(15-30 \mathrm{~cm})$ for subsurface soils at two separate locations for both impacted and un-impacted area and bulked together to obtain a representative of the depth and zones. Soil samples were collected in a sterile polyethylene bag from the contaminated site before excavation, 30, 60, 90 and 120 days after excavation and transported to the laboratory for immediate analysis.

\section{iii. Samples Analysis}

The representative samples were air dried, sieved through $2 \mathrm{~mm}$ size sieve and stored in a plastic bag for analysis. The $\mathrm{pH}$ was measured as described by Smith and Smith [21] using $\mathrm{pH}$ meter (model: Jenway). Twenty $(20 \mathrm{~g})$ of soil samples were weighed and suspended in $50 \mathrm{ml}$ of distilled water and properly stirred. The distribution of sizes of particles (\% clay, sand and silt) and texture were determined using the method of [22]. The electrical conductivity was measured using conductivity bridge (Chandos conductivity model A19 Bridge). Soil organic carbon was determined by the wet combustion method of Walkleyand Black [23] and the total nitrogen was estimated by the Kjeldahl digestion technique [22;23;24]. The chloride concentration was obtained by titration with 
$0.06 \mathrm{M}$ Silver nitrate solution using potassium chromate as indicator and total hydrocarbon count was determined using the method described by Walkleyand Black [23].

\section{Results}

Table I: Physicochemical Parameters of Polluted Soil before Excavation

\begin{tabular}{|c|c|c|c|c|c|c|c|c|}
\hline \multirow[t]{2}{*}{ Parameters } & \multicolumn{2}{|c|}{ Control } & \multicolumn{2}{|c|}{ Litfle impact } & \multicolumn{2}{|c|}{ Medium impact } & \multicolumn{2}{|c|}{ Heavy impact } \\
\hline & $0-15 \mathrm{~cm}$ & $15-30 \mathrm{~cm}$ & $0-15 \mathrm{~cm}$ & $15-30 \mathrm{~cm}$ & $0-15 \mathrm{~cm}$ & $15-30 \mathrm{~cm}$ & 0-15icm & $15-30 \mathrm{~cm}$ \\
\hline $\mathrm{pH}$ & $4.99=0.07^{k} \geq \mathrm{II}$ & $5.08 \pm 0.01^{*}$ z⿺ & $5.2 \pm 0.14$ & $4.86=0.08^{* 25}$ & $4.44 \pm 0.06^{k_{I}}$ & $4.35=0.12$ & $4.61 \pm 0.05^{\times a d}$ & $5.08 \pm 0.01^{* 2 k}$ \\
\hline $\mathrm{E} . \mathrm{C}(\mathrm{wSicm})$ & $108=1.41^{\mathrm{k} b \mathrm{~h}}$ & $63.7 \pm 0.14^{\mathrm{x} z \mathrm{xt}}$ & $50.3=0.28^{* 2}$ & $57.65 \pm 7.00$ & $126.5 \pm 24.32$ & $54.55=0.91^{* 8}$ & $1025 \pm 226$ & $112.65=2.05^{*}=1$ \\
\hline Organic C. (\%) & $2.49=0.13^{\mathrm{k} z}$ & $15.65 \pm 0.91^{\text {*b }}$ & $2.80 \pm 1.14$ & $2.12=0.31^{* 3 \hat{b}}$ & $7.44 \pm 0.09^{k_{2}}$ & $17.8=0.14$ & $31.00=0.28$ & $16.55 \pm 0.35^{* 28}$ \\
\hline Total Nitrogen & $0.4 \pm 0.14$ & $0.29 \pm 0.03^{x_{2} x}$ & $0.16 \pm 0.05$ & $0.14=0.01^{\text {xid }}$ & $0.11 \pm 0.01$ & $0.09 \pm 0.003^{* x}$ & $0.14 \pm 0.01$ & $0.25 \pm 0.07$ \\
\hline Chloride (mg kg) & $21.72 \pm 2.38^{* \Xi}$ & $63.07 \pm 1.59^{*}: \hat{x}$ & $24.95=0.23$ & $20.05=0.23^{\times \mathrm{j}}$ & $68.71 \pm 1.72^{* z}$ & $67.32=1.52$ & $24.03 \pm 1.43$ & $6.56 \pm 0.15^{* 3 t}$ \\
\hline
\end{tabular}

Results are given as Mean \pm standard deviation

Key:

E.C $=$ Electrical Conductivity

$* a b$ denotes significant difference between control and little impact $(\mathrm{P}<0.05)$

$*$ ac denotes significant difference between control and Medium impact $(\mathrm{P}<0.05)$

$*$ ad denotes significant difference between control and Heavy impact $(\mathrm{P}<0.05)$

Table II: Physicochemical Parameters of Impacted Soil 30 Days after Excavation

\begin{tabular}{|c|c|c|c|c|c|c|}
\hline \multirow[t]{2}{*}{ Parameters } & \multicolumn{2}{|c|}{ Little Impact } & \multicolumn{2}{|c|}{ Medium Impact } & \multicolumn{2}{|c|}{ Heavy Impact } \\
\hline & $0.15 \mathrm{~cm}$ & $15.30 \mathrm{~cm}$ & $0.15 \mathrm{~cm}$ & $15.30 \mathrm{~cm}$ & $0.15 \mathrm{~cm}$ & $15.30 \mathrm{~cm}$ \\
\hline $\mathrm{pH}$ & $8.1 \pm 0.14^{\circ \mathrm{x}}$ & $73=0.14$ & $7.5=0.14$ & $7.7=0.14$ & $7.4=0.14^{* x}$ & $7.3=0.14$ \\
\hline$E C(\mu S \mathrm{~cm})$ & $349 \pm 1.41^{* 26}$ & $78.5 \pm 2.12 * 2$ & $146 \pm 1.41^{\circ} \times 5$ & $160 \pm 1.41 * 2 \cdot 6$ & $59.5 \pm 2.13^{*} \mathrm{k} * \mathrm{k}$ & $28.5=2.12 * \mathrm{k} * \mathrm{kt}$ \\
\hline Organic C. (96) & $3.61=0.12^{*}=$ & $2.51 \pm 0.13^{*} \cdot 1 k$ & $2.01 \pm 0.13 \cdot 1 k$ & $1.44 \pm 0.08^{*}$ & $2.13 \neq 0.23^{*} \mathrm{k}$ & $1.78=0.17^{*} \mathrm{ac}$ \\
\hline Total Nitrogen $(\%)$ & $1.85=0.07$ & $1.5 \pm 0.14$ & $1.6 \pm 0.16$ & $1.4=0.14$ & $1.6 \pm 0.14$ & $1.45 \pm 0.07$ \\
\hline Chloride (mg Kg) & $6234.5=43.1^{* 12}$ & $7753=38.18 * a 5$ & $8927=90.50^{* 12 \times 7 t}$ & $7095.3=7,78^{* *+*} \times$ & $6207 \pm 89.09^{* 7 t}$ & $\left.4491=83.4^{*} a c^{*}\right)$ \\
\hline
\end{tabular}

Results are given as Mean \pm standard deviation

Key:

E.C $=$ Electrical conductivity

*abc denotes significant difference between little impact, medium impact and heavily impacted soil $(\mathrm{P}<0.05)$

*ab denotes significant difference between little impact and medium impacted soil $(\mathrm{P}<0.05)$

$*$ ac denotes significant difference between little impact and heavily impactedsoil $(\mathrm{P}<0.05)$

*bc denotes significant difference between medium impact and heavily impacted soil $(\mathrm{P}<0.05)$

TableIII: Physicochemical Parameters of Impacted Soil 60 Days after Excavation

\begin{tabular}{|c|c|c|c|c|c|c|}
\hline \multirow[t]{2}{*}{ Parameters } & \multicolumn{2}{|c|}{ Little Impact } & \multicolumn{2}{|c|}{ Medium Impact } & \multicolumn{2}{|c|}{ Heavy Impact } \\
\hline & $0-15 \mathrm{~cm}$ & $15-30 \mathrm{~cm}$ & $0-15 \mathrm{~cm}$ & $15-30 \mathrm{~cm}$ & $0-15 \mathrm{~cm}$ & $15-30 \mathrm{~cm}$ \\
\hline $\mathrm{pH}$ & $4.45 \pm 0.21$ & $4.3 \pm 0.14$ & $4.35 \pm 0.07$ & $4.35 \pm 0.07$ & $4.5 \pm 0.14$ & $4.4 \pm 0.14$ \\
\hline E.C $(\mu \mathrm{S} / \mathrm{cm})$ & $209.5 \pm 0.71^{* a b c}$ & $209 \pm 1.41 * a b c$ & $282 \pm 2.82 * a b * b c$ & $320.5 \pm 0.71 * a b * b c$ & $151.5 \pm 2.12 * a c * b c$ & $219.5 \pm 0.71^{* a c * b c}$ \\
\hline Organic C. (\%) & $2.25 \pm 0.21$ & $2.45 \pm 0.07$ & $2.95 \pm 0.21$ & $2.1 \pm 0.14$ & $2.3 \pm 0.28$ & $2.2 \pm 0.14$ \\
\hline Total Nitorgen (\%) & $0.18 \pm 0.02^{* a b}$ & $0.22 \pm 0.03$ & $0.25 \pm 0.01^{* a b * b c}$ & $0.17 \pm 0.02$ & $0.17 \pm 0.01^{* b c}$ & $0.18 \pm 0.01$ \\
\hline Chloride $(\mathrm{mg} / \mathrm{kg})$ & $171.2 \pm 8.62$ & $88.5 \pm 0.16$ & $260.95 \pm 7.00$ & $88.365 \pm 0.37$ & $265.5 \pm 0.56$ & $38.36 \pm 0.37$ \\
\hline
\end{tabular}

Results are given as Mean \pm standard deviation

Key:

E.C $=$ Electrical conductivity

*abc denotes significant difference between little impact, medium impact and heavily impacted soil $(\mathrm{P}<0.05)$

$* a b$ denotes significant difference between little impact and medium impacted soil $(\mathrm{P}<0.05)$

$*$ ac denotes significant difference between little impact and heavily impacted soil $(\mathrm{P}<0.05)$

*bc denotes significant difference between medium impact and heavily impacted soil $(\mathrm{P}<0.05)$ 

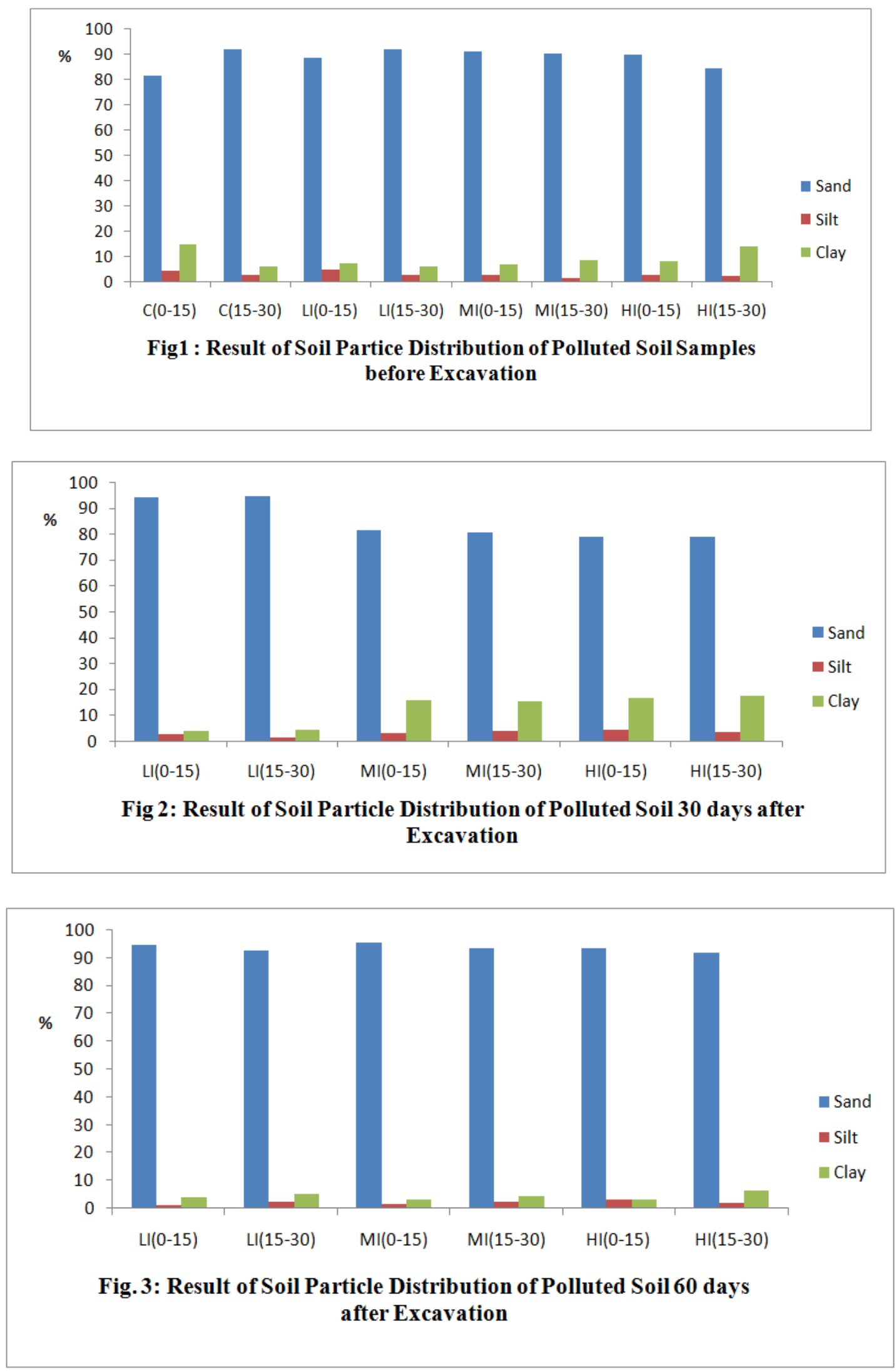


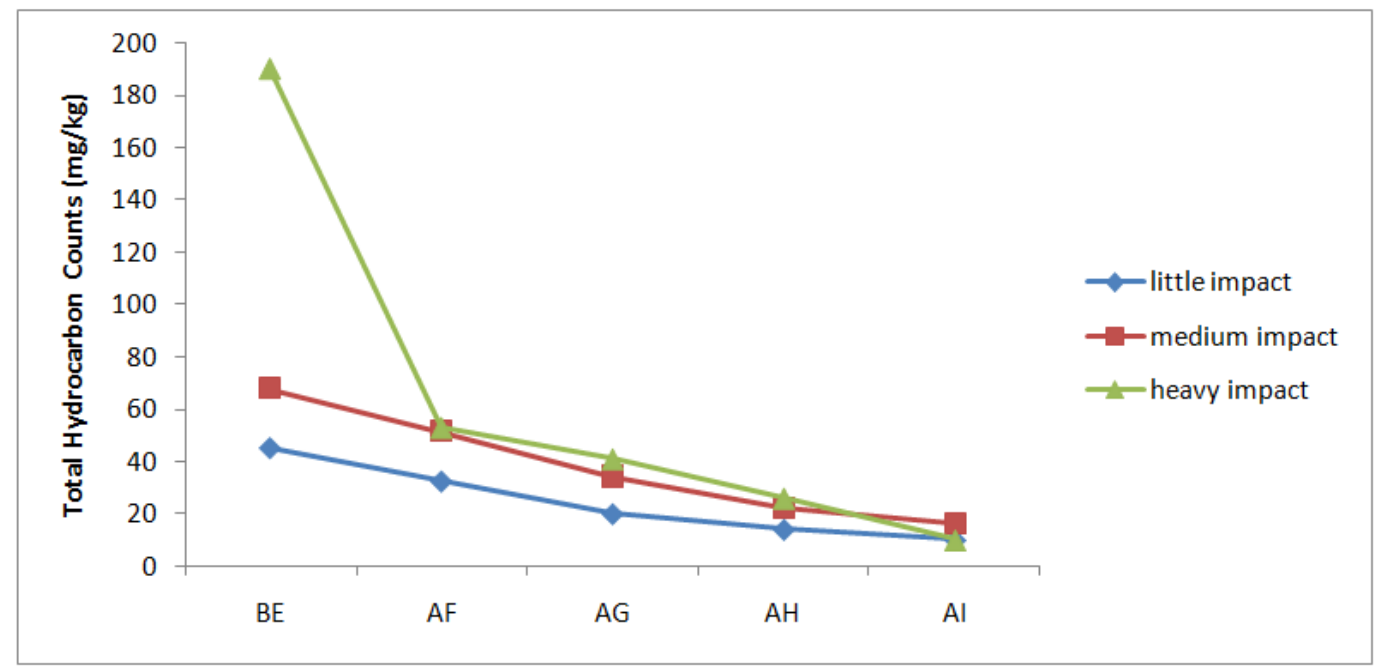

Fig 4: Results of Total Hydrocarbon Count of Petroleum Impacted Soil

Key: BE: Before excavation; AF: 30 days after excavation; AG: 60 days after excavation; AH: 90 days after excavation;AI: 120 days after excavation

\section{Discussion}

The results of this study shown in Tables 1 to 3 revealed that $\mathrm{pH}$ values ranged from $4.35 \pm 0.12$ to $5.20 \pm$ 0.14 before excavation; $7.30 \pm 0.14$ to $8.10 \pm 0.14,30$ days after excavation and $4.30 \pm 0.14$ to $4.50 \pm 0.14,60$ days after excavation. The values of EC were also observed to be between $50.30 \pm 0.28$ to $126.50 \pm 24.32$ before excavation at a depth of $0-15 \mathrm{~cm}$ and $54.65 \pm 0.91$ to $112.65 \pm 2.05$ at $15-30 \mathrm{~cm}$ depth (Table 1 ). The EC values recorded 30 days after excavation were relatively low $(28.50 \mu \mathrm{S} / \mathrm{cm} \pm 2.12)$ at $15-30 \mathrm{~cm}$ depth for heavily impacted reference zone compared to others. At 60 days after excavation, the values were relatively high with the least value being $151.50 \mu \mathrm{S} / \mathrm{cm} \pm 2.12$ (Table 3).

Similarly, organic carbon was relatively low before and after excavation (Tables 1,2 and 3) while nitrogen content and chloride concentration were high 30 days after excavation against before and 60 days after excavation.

The percentage of sand in the polluted site was high for all the reference zones against silt and clay. Meanwhile, total hydrocarbon counts fell considerably with excavation (Figure 4).

The $\mathrm{pH}$ values of the sampleswere relatively low before excavation and 60 days after excavation compared to 30 days after excavation. The $\mathrm{pH}$ values before excavation were however within an acidic range (Table 1).Similarly, $\mathrm{pH}$ values between the range; 5.5 to 8.8 is known to favour the rate of biodegradation in petroleum contaminated soil [1]. However, the results of the $\mathrm{pH}$ values obtained before excavation was found to be lower than the range required for effective biodegradation. This is an indication that the spillage was massive enough to kill the microbial population present in the soil, thereby making bioremediation impossible as the first and only remedy to the oil spillage. Upon excavation (30 days), it was observed that the $\mathrm{pH}$ values rose considerably (Table 2) enough to allow microbial action in the remediation process. This is an indication that excavation could be a palliative measure in the treatment of petroleum contaminated site. Statistical analysis showed that there was significant difference between the $\mathrm{pH}$ values obtained before and after excavation.

The result of electrical conductivity of soil samples before excavation were found to be generally low for both top soil and sub-soil; the range being $50.30 \pm 0.28$ to $126.50 \pm 24.32(\mu \mathrm{S} / \mathrm{cm})$. Higher values of electrical conductivity were measured 60 days after excavation; the range being $151.50 \pm 2.12$ to $320.50 \pm 0.71(\mu \mathrm{S} / \mathrm{cm})$ and similar higher values for 30 days and 120 days after excavation. This indicates that salt content of oil impacted soil are lower. Similar observation was made by Benka-Coker and Ekundayo [27]. However, significant difference exists between the control and little impacted region of the top soil as well as in the subsoil between control, medium and heavily impacted zones.

From this study, it is evident that the oil spill at Ofagbe town, Delta state, Nigeria resultedin an increase in organic carbon content of impacted soils, (medium and heavy). Similar increases have been reported by BenkaCoker and Ekundayo[27] and Ekundayo and Obuekwe[28]. However, the values recorded for organic carbon were found to decline 30 days and 60 days after excavation. This is an indication that excavation is a means of reducing 
significantly, the carbon content of oil impacted soil. In all the samples examined, the percentage of sand was relatively high, compared to other particles present in the soil (Figures 1-3). This high sand content of the soils is characterized by sand formed on unconsolidated coastal plain sand and sandstones [29]. However, the significant effect of the oil spill on the sand content of affected soils of Ofagbe town when compared with that of the control can be observed in Figure 1 to 3. Since sandy soil is not fit for crop production, the presence of oil spill which significantly increased the percentage of sand in the soil has adverse effect on the fertility of the affected soils. This is as a result of a probable high drainage of oil into the lower horizon of the soil causing aeration problem as the air pores will be blocked with oil and prevent the easy flow of nutrients to the soil [30].

\section{Conclusion}

It is evident that the oil spill at Ofagbe town, Delta state, Nigeria resultedin an increase in organic carbon content of impacted soils, (medium and heavy).The results of total hydrocarbon counts represented in figure 4 shows general enhancement in content ranging from $28.29 \pm 1.02 \mathrm{mg} / \mathrm{kg}$ measured 15 to $30 \mathrm{~cm}$ of little impacted reference zone to $250.87 \pm 8.10 \mathrm{mg} / \mathrm{kg}$ measured in 0 to $5 \mathrm{~cm}$ of heavily impacted zone. For both top and subsoil of the zone taken as control, the total hydrocarbon content was found to be zero. For the top soil, a decrease in the concentration of hydrocarbons 30 days after treatment by $28.2 \%, 65.4 \%$ and $80.58 \%$ of little impact zone, medium impact zone and heavily impacted zone respectively. Similarly, the result of 60 days after excavation shows a decrease of 55.7\%, $74.8 \%$ and $88.0 \%$ for little impact zone, medium impact zone and heavy impact zone. This implies that excavation could be a possible remedy for treating hydrocarbon polluted soil despites its other consequences.

\section{References}

[1]. Abii, T.A. and Nwosu, P.C. (2009). The effect of oil-spillage on the soil of Eleme in Rivers State of the Niger-Delta Area of Nigeria. Research Journal of Environmental Sciences 3(3): 316-320.

[2]. Odu, C.T.I. (1972). Microbiology of soil contaminated with petroleum hydrocarbon. Journal of Environmental Microbiology. 58: 201208.

[3]. Ngobiri, C.N. Ayuk, A.A. Awuoso, I.I. (2007). Differential degradation of hydrocarbon fractions during bioremediation of crude of polluted sites in Nigeria Delta area. J. Chem. Soc. Nig. 32: 151-158.

[4]. Osuji, E.C. and Ezebuiro, P.E. (2006). Hydrocarbon contamination of typical mangrove floor in Niger Delta region. International Journal of Environmental Science and Technology. 3(3): 313-320.

[5]. Amadi, A. and Antai, S.P. (1992). The socio-economic effects of oil spillage on agriculture in the Niger-Delta. International Journal of Biochemphysics. 1: 5-8.

[6]. Awobajo, A.O. (1981). An analysis of oil spill incidence in Nigeria, In proceedings of an international seminar on the petroleum industry and the Nigerian environment, NNPC, Lagos, Nigeria.

[7]. Okpokwasili, G.C. and Amanchukwu, S.C. (1988). Petroleum hydrocarbon degradation by Candida species. Environment International. 14: $243-247$.

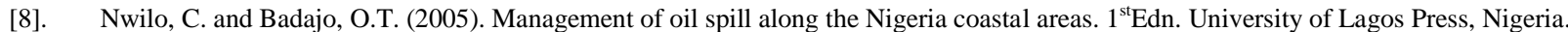

[9]. Okoli, A.I and Orinya, S. (2013). Oil Pileline Vandalism and Nigeria National Security. Global Journal of Human Social Science; Vol. 131.

[10]. DPR (1997). Department of petroleum resources, annual reports. Department of Petroleum Resources.Pp. 191.

[11]. Rheinheimer, G. (1980). Aquatic Microbiology. John Wiley and Sons, New York. 260 pp

[12]. Odu, C.T.I., Nwoboshi, L.C. and Esuruoso, O.F. (1985). Environmental studies (Soils and vegetation) of the Nigerian Agip Oil Company operation areas, in Proceeding of an International Seminar on the Petroleum Industry and the Nigerian Environment. NNPC, Lagos, Nigeria. Pp. 274-283.

[13]. Okoko, K.A.B. and Ibaba, I.S. (1999). Oil spillages and community disturbances: The SPDC and the Niger Delta experience. Journal of Oil Politics. 2: 6-69.

[14]. Amadi, A. (1990). Effects of petroleum hydrocarbon on the ecology of microbial species and performance of maize and cassava. PhD. Thesis, University of Ibadan, Nigeria.

[15]. Amadi, A., Dickson, A. and Maate, G.O. (1993). Remediation of oil polluted soils. In: effect of organic and inorganic nutrient supplements on the performance of maize (Zea may L). Water Air Soil Pollution. 66: 59-76.

[16]. Osuji, L.C., Egbuson, E.J. and Ojinnaka, C.M. (2006). Assessment and treatment of hydrocarbon inundated soils using inorganic nutrient (N-P-K) supplements: II. A case study of Eneka oil spillage in Niger Delta, Nigeria. Environmental Monitoring and Assessment. 115: 265-278.

[17]. Ogboghodo, T.A., Azenabor, U.F. and Osemwota, I.O. (2005). Amelioration of a crude oil polluted soil with poultry manure and effects on growth of maize and some soil properties. Journal of Plant Nutrition. 28: 21-32.

[18]. Atlas, R.M. (1988). Biodegradation of hydrocarbons in the environment In: Environmental Biotechnology. Omena G.S. Edplenum Press, New York.

[19]. National Research Council (NRC), (1985). Oil in the sea; inputs, fates and effects. National Academy Press, Washington D.C.

[20]. Cunningham, S.D. and Berti, W.R. (1993). Remediation of contaminated soil with green plants: An overview. In: Vitro cellular and Developmental Biology, Plant 29: 207-212.

[21]. Smith, G.N. and Smith, G.G.N. (1998). Elements of soil mechanics. $7^{\text {th }}$ edn. Blackwell Science, Oxford.

[22]. Bouyoucos, G.H. (1951). A recalibration of the hydrometer for making mechanical analyses of soil. Agronomy Journal. 43: 434-438.

[23]. Walkley, A. and Black, T.A. (1934). An examination of the Degtjareff method for determining soil organic matter and proposed modification of chronic acid titration method. Soil Science. 37: 29-38. 
[24]. AOAC (1975). Methods of soil analysis, $12^{\text {th }}$ edn. Washington D.C. Association of Official Analytical Chemist.

[25]. Page, A.L. Miller, R.H. and Keeney, D.R. (1982). Methods of soil analysis part 2. Chemical and Microbiological Properties, $2^{\text {nd }}$ edn. Pp. 1159.

[26]. Jackobsen, S.T. (1992). Chemical reaction and air charge during the decomposition of organic matter. Resource Conservation and Recycling. 6:529-539.

[27]. Benka-Coker, M.O. and Ekundayo, J.A. (1995). Effects of oil spill on soil physic-chemical properties of a spill site in the Niger Delta area of Nigeria. Environmental Monitoring and Assessment. 36: 93-104.

[28]. Ekundayo, E.O. and Obuekwe, O. (2000). Effects of an oil spill on soil physic-chemical properties of a spill site in a typicudipsamment of the Niger Delta Basin of Nigeria. Environmental Monitoring and Assessment. 60: 235-249.

[29]. FDALR (1987). Reconnaissance, soil map of Nigeria. Federal Ministry of Agriculture and Rural Development, Abuja.

[30]. Chinda, A.C. and Braide, S.A. (2000). The impact of soil spills on the ecology and economy of Niger Delta. Proceedings of the workshop on sustainable remediation development technology, held at the institute of pollution studies, Rivers State University of Science and Technology, Port Harcourt. Pp. 1-1. 